Syntax Literate : Jurnal Ilmiah Indonesia p-ISSN: 2541-0849

e-ISSN : 2548-1398

Vol. 6, No. 3, Maret 2021

\title{
PENGARUH MOTIVASI DAN KEPEMIMPINAN TERHADAP KINERJA KARYAWAN PT. BANK RAKYAT INDONESIA CABANG KARAWANG
}

\author{
Shinta Kamilia Wulandari, Banuara Nadeak dan Sonny Hersona \\ Universitas Singaperbangsa Karawang \\ Email: 1910632020036@student.unsika.ac.id, banuara.nadeak@fe.unsika.ac.id dan \\ sonny.hersona@fe.unsika.ac.id
}

\begin{abstract}
This Study aims to determine the effect of motivation and leadership on employee performance PT. BRI Branch Karawang. Data collection is done by distributing questionnaires with total sample of 48 respondens and using a quantitative descriptive approach. Therefore, the data analysis used is statistical analysis in the form of multiple linier regression test. The results of this study indicate that partially and simultaneously variable motivation and leadership affect the performance of PT BRI Branch Karawang employees. This is evidenced from the results of the simultaneous test (F Test) and the result of the Partial Test ( $t$ Test) also showing significant values of the two independent variables that support the hypothesis. Therefore the test result from this study state that there is a simultaneous influence between the variables of motivation and leadership on the performance of the PTBRI Branch Karawang.
\end{abstract}

Keywords: motivation, leadership, employee performance

\begin{abstract}
Abstrak
Penelitian ini bertujuan untuk mengetahui pengaruh motivasi dan kepemimpinan terhadap kinerja karyawan PT. BRI Cabang Karawang. Pengumpulan data dilakukan dengan penyebaran kuesioner dengan jumlah sampel 48 responden dan dengan menggunakan pendekatan deskritif kuantitatif. Karena itu analisis yang digunakan adalah analisi statistik dalam bentuk uji regresi linier berganda. Hasil Penelitian ini menunjukan bahwa secara pasrsial dan simultan variabel motivasi dan kepemimpinan berpengaruh terhadap kinerja karyawan PT. BRI Cabang Karawang. Hal ini dibuktikan dari hasil uji simultan (Uji F) dan hasil Uji Parsial (Uji t) juga menunjukkan nilai signifikan dari dua variabel bebas yang mendukung hipotesa. Oleh karena itu hasil uji menyatakan bahwa terdapat pengaruh secara simultan antara variabel motivasi dan kepemimpinan terhadap kinerja PT BRI Cabang Karawang.
\end{abstract}

Kata kunci: motivasi, kepemimpinan, kinerja karyawan 
Coresponden Author

Email: 1910632020036@ student.unsika.ac.id Artikel dengan akses terbuka dibawah lisensi

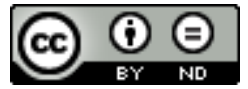

\section{Pendahuluan}

Manajemen sumber daya manusia sebagai pilar yang mempunyai peranan utama bagi perusahaan, dalam mendukung strategi dan kebijakan secara kesatuan. Menurut (Edwin B.Flippo, 2015). Manajemen Sumber Daya Manusia dapat diartikan sebagai kegiatan perencanaan, pengorganisasian, pengarahan dan pengendalian atas pengadaan tenaga kereja, pengembangan, kompensasi, integrasi, pemeliharaan dan pemutusan hubungan kerja dengan sumber daya manusia untuk mencapai sasaran perorangan, organisasi dan masyarakat.

Sumber daya manusia adalah bagian penting dalam aktivitas kerja. Karena hal tersebut akan berhubungan dengan masalah kualitas kerja dan pencapaian kerja (Saridawati, 2018). Sumber daya manusia sebagai karyawan merupakan sesuatu yang sangat penting karena merupakan ujung tombak perusahaan dalam mewujudkan tujuan perusahaan. Betapapun majunya teknologi, perkembangan informasi, tersedianya modal dan memadainya bahan, jika tanpa Sumber Daya Manusia sulit bagi perusahaan itu untuk mencapai tujuannya.

Dalam rangka untuk menunjang agar aktifitas manajemen dalam perusahaan berjalan dengan baik, perusahaan harus memiliki karyawan yang berkompeten di bidangnya masing-masing, berpengetahuan dan memiliki keterampilan yang memadai, memiliki keinginan untuk maju dan manajemen harus berusaha untuk mengelola perusahaan semaksimal mungkin, sehingga kinerja karyawan dapat meningkat. Menurut (Hasibuan, 2015) menyatakan Kinerja adalah keluaran yang dihasilkan oleh fungsi-fungsi atau indikator-indikator suatu pekerjaan atau suatu profesi dalam waktu tertentu berdasarkan kecakapan, pengalaman, kesungguhan dan waktu. Kinerja berasal dari kata Job Performance atau actual performance yang berarti prestasi kerja atau prestasi sesungguhnya yang dicapai seseorang. Pengertian kinerja menurut (Mangkunegara, 2016) adalah hasil kerja secara kualitas dan kuatitas yang dicapai oleh karyawan dalam melaksanakan tugas dan fungsinya sesuai dengan tanggung jawab yang telah diberikan kepadanya. Upaya-upaya untuk meningkatkan kinerja karyawan merupakan tantangan serius bagi manajemen perusahaan karena keberhasilan perusahaan dalam mencapai tujuan dan kelangsungan hidup perusahaan itu sendiri bergantung pada kualitas kinerja sumber daya manusia yang terlibat dalam perusahaan. Sumber daya manusia merupakan aset terpenting perusahaan karena perannya sebagai subyek pelaksana kebijakan dan kegiatan operasional perusahaan. Agar perusahaan tetap eksis maka harus berani menghadapi tantangan dan implikasinya yaitu menghadapi perubahan dan memenangkan persaingan.

Perusahaan tidak hanya mengharapkan sumber daya manusia yang cakap dan terampil, akan tetapi perusahaan mengharapkan karyawannya mau bekerja dengan 
giat dan berkeinginan untuk mencapai hasil kerja yang optimal. Menurut (Wibowo, 2016) menjelaskan teori motivasi McClelland yaitu proses psikologis yang membangkitkan dan mengarahkan perilaku pada pencapaian tujuan. Dorongan motivasi memfokuskan kepada (1) Motivasi Berprestasi adalah dorongan yang dimiliki banyak orang untuk mengejar dan mencapai tujuan menantang. (2) Motivasi untuk berafiliasi merupakan dorongan untuk berhubungan dengan orang atas dasar social. (3) Motivasi akan kekuasaan adalah dorongan untuk mempengaruhi orang, melakukan pengawasan dan pengubah situasi. Ini bukan perasaan senang yang relatif terhadap hasil berbagai pekerjaan sebagaimana halnya kepuasan, tetapi lebih merupakan perasaan sedia/rela bekerja untuk mencapai tujuan pekerjaan.

Sesuai dengan hasil penelitian terdahulu (Liandy Lumban Tobing, 2021) dengan hasil penelitian menunjukkan bahwa Motivasi secara parsial berpengaruh terhadap kinerja karyawan. Hal inipun selaras dengan penelitian (Ekhsan, 2019) dalam penelitiannya dengan hasil penelitian menunjukkan bahwa Motivasi kerja berpengaruh signifikan terhadap kinerja karyawan PT. Syncrum Logistics. Hal ini menunjukan bahwa semakin tinggi motivasi karyawan maka semakin tinggi kinerja karyawan. Menurut penelitian (Pane,2019) bahwa motivasi berpengaruh positif terhadap kinerja karyawan. Menurut (Liyas,2018) bahwa motivasi berpengaruh terhadap kinerja karyawan akan tetapi tidak signifikan. Menurut (Hidayatulah, 2018) dengan hasil penelitian bahwa Motivasi berpengaruh secara parsial maupun simultan terhadap kinerja karyawan. Akan tetapi tidak sejalan dari hasil penelitian dari (Inaray, 2016) dengan hasil penelitian bahwa motivasi tidak berpengaruh secara signifikan terhadap kinerja karyawan.

Faktor Penting lainnya yang menentukan kinerja karyawan adalah adalah kepemimpinan. Anoraga (Hartanto, 2016) menjelaskan bahwa kepemimpinan adalah kemampuan untuk mempengaruhi pihak lain melalui komunikasi baik langsung ataupun tidak langsung untuk bertujuan menggerakkan orang-orang agar dengan penuh pengertian, kesadaran, dan senang hati bersedia mengikuti kehendak pimpinan tersebut. Faktor kepemimpinan ini sejalan dengan penelitian dari (Fadude, Tawas, \& Poluan, 2019) dengan hasil penelitian menunjukkan bahwa kepemimpinan secara parsial berpengaruh terhadap kinerja karyawan. Dan sejalan pula dengan hasil penelitian (Parashakti \& Setiawan, 2019) dengan hasil penelitian menunjukkan bahwa gaya kepemimpinan dan motivasi secara simultan berpengaruh signifikan terhadap kinerja karyawan dan secara parsial gaya kepemimpinan berpengaruh terhadap kinerja karyawan serta motivasi secara parsial berpengaruh secara signifikan terhadap kinerja karyawan.

PT. Bank Rakyat Indonesia Cabang Karawang adalah salah satu perbankan milik pemerintah yang ada di Kabupaten Karawang. Kepemimpinan selama beberapa tahun mengalami pergantian pemimpin. Beberapa hal yang ada dalam lingkungan Bank, tentu mengalami beberapa peraturan yang bebeda sesuai dengan siapa yang memimpin pada saat itu. Hal ini dilakukan oleh pimpinan cabang agar karyawan agar tetap menjaga kinerja karyawan demi tercapainya tujuan perusahan. Pimpinan selalu mengutamakan 
keseragaman pada karyawan demi menjaga kualitas kerja karyawan agar tetap memberikan kinerja yang baik.

Persaingan dengan mengedepankan kualitas layanan (service quality) menjadi sedemikian ketatnya dalam memperebutkan pangsa pasar dalam dunia perbankan. Bank-bank umum berkompetisi dengan menawarkan pelayanan terbaik tentunya dengan Sumber Daya Manusia yang baik pula. Salah satu aspek yang mendukung dalam penilaian kinerja yaitu dengan adanya motivasi dari diri setiap karyawan. Bagaimana setiap karyawan selalu ingin memberikan pencapaian terbaiknya dalam kemajuan perusahaan.

Melihat fenomena tersebut diatas untuk mengetahui pengaruh motivasi dan kepemimpinan terhadap kinerja karyawan pada PT. Bank Rakyat Indonesia Cabang Karawang, maka peneliti akan melakukan penelitian di BRI Cabang Karawang.

Tujuan Penelitian.

1. Menganalisis pengaruh Motivasi Karyawan terhadap Kinerja Karyawan pada PT. Bank Rakyat Indonesia Cabang Karawang.

2. Menganalisis pengaruh Kepemimpinan terhadap Kinerja Karyawan pada PT. Bank Rakyat Indonesia Cabang Karawang.

3. Menganalisis pengaruh Motivasi Karyawan dan Kepemimpinan terhadap Kinerja Karyawan pada PT.Bank Rakyat Indonesia Cabang Karawang

\section{Metode Penelitian}

Jenis penelitian yang digunakan adalah penelitian asosiatif. Penelitian Asosiatif adalah penelitian yang bertujuan untuk mengetahui hubungan dua variabel atau lebih. Dalam penelitian ini maka akan dapat dibangun suatu teori yang dapat berfungsi untuk menjelaskan, meramalkan, dan mengontrol suatu gejala (Sugiyono, 2012). Lokasi dan Waktu Penelitian dilakukan di BRI Cabang Karawang selang bulan September Desember 2020. Dengan tahapan Prasurvai, Uji Coba Instrumen, Pengumpulan data, Analisis Data dan Penulisan Laporan.

Responden atau Sampel menurut (Sugiyono, 2017) menyatakan populasi adalah wilayah generalisasi yang terdiri dari obyek atau subyek yang mempunyai kualitas dan karakteristik tertentu yang diterapkan oleh peneliti untuk dipelajari dan kemudian ditarik kesimpulannya. Berdasarkan pengertian tersebut, ukuran populasi dalam penelitian ini adalah 48 orang karyawan di BRI Cabang Karawang. Dikarenakan jumlah populasi dalam penelitian ini relatif kecil, maka sampel yang diambil adalah seluruh jumlah populasi sesuai dengan (Sugiyono, 2017) menyatakan sampling jenuh adalah teknik penentuan sampel dimana semua anggota populasi digunakan sebagai sampel.

Pengumpulan Data yang dibutuhkan dalam penelitian adalah data primer dan sekunder. Data sekunder adalah melalui studi pustaka. Data primer merupakan data yang dikumpulkan secara langsung oleh peneliti dengan menerapkan teknik survei yaitu memberikan sejumlah kuesioner untuk variabel motivasi, kepemimpinan dan kinerja karyawan. Kuesioner dalam penelitian ini menggunakan Skala Likert Menurut (Sugiyono, 2012) skala likert digunakan untuk mengukur sikap,pendapat, dan persepsi 
seseorang atau sekelompok orang tentang fenomena sosial. Skala Likert dengan penilaian 1-5 dengan angka 1 menyatakan sangat tidak setuju (STS), angka 2 menyatakan tidak setuju (TS), angka 3 menyatakan kurang setuju (KS), angka 4 menyatakan setuju (S), dan angka 5 menyatakan sangat setuju (SS). Model hubungan antara ketiga variabel penelitian ini dapat digambarkan sebagai berikut:

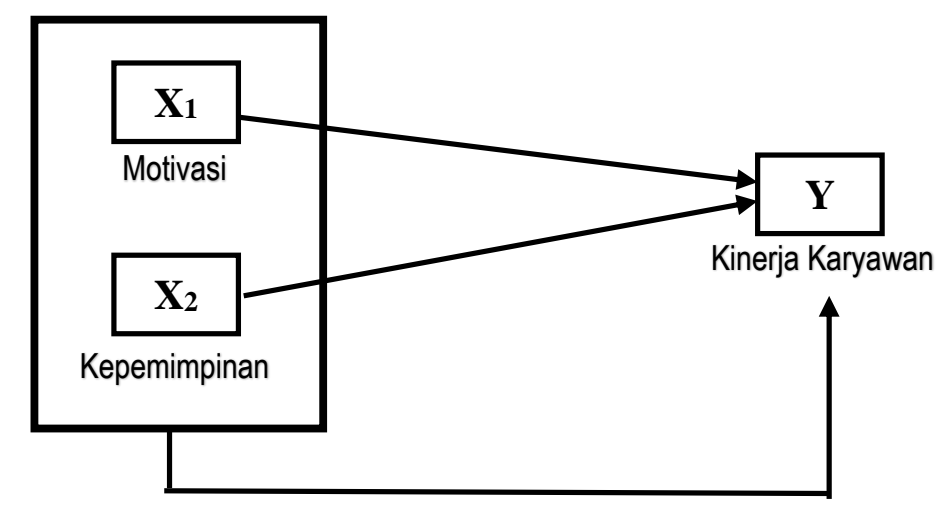

\section{Gambar 1}

Hipotesis Penelitian:

Alur Hubungan Antar Variabel Penelitian

1. Diduga Motivasi secara parsial berpengaruh signifikan terhadap Kinerja Karyawan.

2. Diduga Kepemimpinan secara parsial berpengaruh signifikan terhadap Kinerja Karyawan.

3. Diduga Motivasi dan Kepemimpinan secara simultan atau bersama sama berpengaruh signifikan terhadap Kinerja Karyawan.

Setelah data diperoleh dan dikumpulkan kemudian selanjutnya dilakukan uji instrument yaitu dengan uji validitas dan Reliabilitas Uji Validitas Sugiyono (2017) menyatakan pengujian validitas instrumen dilakukan untuk menguji bahwa terdapat kesamaan antara data yang terkumpul dengan data yang sesungguhnya terjadi pada objek yang diteliti. Dalam pengujian ini menggunakan 48 responden untuk menentukan valid atau tidaknya suatu kuesioner. Suatu kuesioner dinyatakan valid apabila $r$ hitung (tabel Correlated Item Total Correlation > $r$ tabel (tabel product moment) atau bernilai positif. Adapun nilai $r$ tabel untuk respoden 48 dengan df 2 dan tingkat kesalahan 5\% Angka $r$ tabel nya adalah sebesar 0,2403. Pengujian validitas menunjukkan semua butir pernyataan dalam kuesioner yang digunakan dalam penelitian ini dinyatakan valid karena memiliki nilai rhitung > r-tabel.

Uji Reliabilitas Indrawati (2015:155) Reliabilitas adalah menyangkut tingkat kepercayaan, keterandalan, konsistensi, atau kestabilan hasil suatu pengukuran. Teknik perhitungan koefisien reliabilitas yang digunakan adalah koefisien reliabilitas Cronbach's Alpha dengan rumus: 


$$
\begin{aligned}
& r=\left[\frac{k}{(k-1)}\right]\left[1-\frac{\sum \sigma_{b}{ }^{2}}{\sigma_{t}{ }^{2}}\right. \\
& \text { Keterangan: } \\
& r \quad=\text { koefisien reliabilitas instrument (cronbach alpha) } \\
& k \quad=\text { banyakrya butir pertaryacon atau banyalnya soal } \\
& \sum \sigma_{b}{ }^{2}=\text { total varians butir } \\
& \sigma_{z}{ }^{2} \quad=\text { total varians }
\end{aligned}
$$

Untuk meminimalisasi kesalahan pengolahan data, pengujian reliabilitas dilakukan dengan program SPSS 21.0 for Windows. Pada penelitian ini, uji reliabilitas menggunakan tingkat kesalahan 5\%, sehingga nilai $\mathrm{r}$ Tabel yang digunakan sebesar 0,2403. Maka tiap item pernyataan akan dinyatakan reliabel jika nilai Cronbach's Alpha $>0,2403$.

\section{Tabel 1}

Hasil perhitungan Reliabilitas

\begin{tabular}{cccc}
\hline Variabel & $\begin{array}{c}\text { Cronbach's } \\
\text { Alpha }\end{array}$ & $\begin{array}{c}\mathbf{r} \\
\text { Tabel }\end{array}$ & Hasil \\
\hline Motivasi & 0,661 & 0,2403 & Reliabel \\
\hline Kepemimpinan & 0,794 & 0,2403 & Reliabel \\
\hline $\begin{array}{c}\text { Kinerja } \\
\text { Karyawan }\end{array}$ & 0,829 & 0,2403 & Reliabel \\
\hline
\end{tabular}

Pengujian selanjutnya adalah melakukan uji hipotesis atau uji statistik Uji-t. Tujuan pengujian ini untuk mengetahui apakah variabel bebas (X) secara parsial (sendiri-sendiri) berpengaruh terhadap variabel terikat (Y). Menurut Abdillah dan Hartono (2015), nilai path coefficient menununjukkan tingkat signifikansi dalam pengujian hipotesis. Kemudian melakukan Uji $F$, tujuan pengujian uji $F$ ini untuk menguii apakah semua variabel bebas (X1 dan X2) yang dimasukkan mempunyai pengaruh secara bersama sama (simultan) terhadap variabel terikat (Y) menurut Ghojali (2012: 98). Ada dua pedoman untuk hipotesis Uji F pertama dengan membandingkan nilai Signifikansi dengan probabilitas hasil output Annova, jika nilai sig < Output Annova maka hipotesis di terima. Kedua dengan membandingkan Nilai F hitung dengan $\mathrm{F}$ tabel. Jika $\mathrm{F}$ hitung > F tabel maka hipotesis diterima dan untuk mengukur seberapa jauh kemampuan model dalam menerangkan variasi variabel bebas. Maka kita melakukan analisis Koefisien determinasi (r2). Kemudian melakukan analisis Regresi Linear Berganda untuk memprediksikan bagaimana keadaan (naik turunnya) variabel bebas, bila dua atau lebih variabel bebas sebagai faktor prediksi (dinaik turunkan nilainya). 


\section{Hasil dan pembahasan}

1. Uji hipotesis atau uji statistik Uji-t untuk variabel Motivasi dan kepemimpinan terhadap Kinerja Karyawan dengan signifikansi yang digunakan $(\alpha)$ adalah 5\%, yang artinya peneliti percaya bahwa 95\% dari keputusan adalah benar.

$\mathrm{H}_{0}$ diterima jika nilai $\mathrm{t} \leq 1.67943(\mathrm{H} 0: \mathrm{t} \leq 1.67943)$

$\mathrm{H}_{1}$ diterima jika nilai $\mathrm{t}>1.67943(\mathrm{H} 1: \mathrm{t}>1.67943)$

\section{Tabel 2}

Hasil perhitungan uji t kedua variabel bebas Coefficients $^{\text {a }}$

\begin{tabular}{|c|c|c|c|c|c|c|}
\hline \multirow{2}{*}{\multicolumn{2}{|c|}{ Model }} & \multicolumn{2}{|c|}{$\begin{array}{c}\text { Unstandardized } \\
\text { Coefficients } \\
\end{array}$} & \multirow{2}{*}{$\begin{array}{c}\begin{array}{c}\text { Standardized } \\
\text { Coefficients }\end{array} \\
\text { Beta }\end{array}$} & \multirow[t]{2}{*}{$\mathrm{t}$} & \multirow[t]{2}{*}{ Sig. } \\
\hline & & B & Std. Error & & & \\
\hline \multirow{3}{*}{1} & (Constant) & 7.207 & 4.152 & & 1.736 & .089 \\
\hline & Motivasi & .439 & .150 & .278 & 2.933 & .005 \\
\hline & $\begin{array}{l}\text { Kepemimpin } \\
\text { an }\end{array}$ & .828 & .118 & .664 & 7.010 & .000 \\
\hline
\end{tabular}

a. Dependent Variable: Kinerja.Kary

Sumber: Hasil olah dta menggunakan SPSS.21.0

Dari pengolahan data menggunakan SPPS 21.0 maka:

1) Nilai $t$ hitung untuk variabel motivasi karyawan terhadap kinerja karyawan sebesar 2,933 dan t Tabel sebesar 1,67943. Maka t hitung > dari t tabel artinya variabel motivasi (X1) berpengaruh positif dan signifikan terhadap Kinerja Karyawan.

2) Nilai t hitung untuk variabel Kepemimpinan terhadap kinerja karyawan sebesar 7,010 dan t Tabel sebesar 1,67943. Maka t hitung > dari t tabel artinya variabel kepemimpinan (X2) berpengaruh positif dan signifikan terhadap Kinerja Karyawan.

\section{a. Uji F}

Hasil Uji F pada penelitian pengaruh Motivasi dan Kepemimpinan terhadap Kinerja Karyawan adalah sebagai berikut:

\section{Tabel 3}

\section{Uji Simultan (Uji F) ANOVAa}

\begin{tabular}{rlrrrrr}
\hline Model & & Sum of & Dfi T & \multicolumn{1}{c}{ Mean } & F & Sig. \\
& & Squares & & \multicolumn{1}{c}{ Square } & & \\
\hline \multirow{2}{*}{1} & Regression & 1341.426 & 2 & 670.713 & 60.137 & $.000^{\mathrm{b}}$ \\
& Residual & 501.887 & 45 & 11.153 & & \\
& Total & 1843.313 & 47 & & & \\
\hline
\end{tabular}

a. Dependent Variable: Kinerja.Kary 
b. Predictors: (Constant), Kepemimpinan, Motivasi

Sumber : Hasil olah dta menggunakan SPSS.21.0

Dari tabel uji f diatas diketahui bahwa $\mathrm{f}$ hitung adalah sebesar 60,137 sementara nilai $\mathrm{f}$ tabel dengan sampel 48 dan dua variabel bebas yaitu sebesar 3,20. Maka f-hitung > f-tabel yaitu 60,137> 3,20 artinya variabel motivasi dan kepemimpinan secara simultan berpengaruh positif dan signifikan terhadap kinerja karyawan.

\section{b. Analisis Koefisien Determinasi}

Hasil Uji Koefisien determinasi (r2) pada penelitian pengaruh Motivasi dan Kepemimpinan terhadap Kinerka Karyawan adalah sebagai berikut:

\section{Tabel 4}

Koefisien Determinasi

\begin{tabular}{lrrrr}
\hline Model & R & R Square & $\begin{array}{c}\text { Adjusted R } \\
\text { Square }\end{array}$ & $\begin{array}{r}\text { Std. Error of } \\
\text { the Estimate }\end{array}$ \\
\hline 1 & $.853^{\mathrm{a}}$ & .728 & .716 & 3.33962 \\
\hline
\end{tabular}

a. Predictors: (Constant), Kepemimpinan, Motivasi

Sumber: Hasil olah dta menggunakan SPSS.21.0

Dari tabel diatas diketahui bahwa koefisien determinasi (R Square) yang diperoleh adalah sebesar 0,728. Hal ini berarti 72,8\% motivasi dan kepemimpinan berpengaruh terhadap kinerja karyawan sedangkan sisanya yaitu sebesar 27,2\% kinerja karyawan dipengaruhi oleh variabel variabel lainnya yang ditidak diteliti dalam penelitian ini.

\section{c. Analisis Regresi Linear Berganda}

Berdasarkan tabel 2 didapatkan persamaan regresi linear berganda sebagai berikut.

$\mathrm{Y}=7,207+0,439 \mathrm{X}_{1}+0,828 \mathrm{X}_{2}$

Dimana:

$\mathrm{X}_{1}=$ Motivasi

$\mathrm{X}_{2}=$ Kepemimpinan

$\mathrm{Y}=$ Kinerja Karyawan

Penjelasan sebagai berikut.

1) Nilai konstanta adalah sebesar 7,207 memberikan pengertian bahwa jika Motivasi (X1) dan Kepemimpinan (X2) secara serempak atau bersama sama tidak mengalami perubahan atau sama dengan nol maka besarnya kinerja karyawan (Y) sebesar 7,207.

2) Nilai koefisien regresi variabel Motivasi $\left(X_{1}\right)$ terhadap variabel Kinerja (Y) adalah sebesar 43,9\%. Ini memberikan pengertian jika variabel Motivasi $\left(\mathrm{X}_{1}\right)$ naik sebesar $1 \%$, akan meningkatkan variabel Kinerja (Y) sebesar 43,9\% dengan asumsi variabel lainnya tetap. Hal ini mengartikan semakin meningkatnya motivasi setiap karyawan maka akan semakin 
meningkat pula kinerja karyawan. Berdasarkan hasil jawaban dari 48 responden yang diperoleh dari kuisioner menunjukkan bahwa motivasi berada pada skala baik. Hal ini selaras dengan Kaswan dan Ade Sadikin Akhyadi (2015:83) yang berpendapat bahwa motivasi mampu meningkatkan kinerja seseorang, baik itu produktivitas, kedisiplinan, kreativitas, rasa tanggung jawab bahkan kepuasan karyawan tersebut. Penelitian ini sejalan dengan penelitian yang dilakukan oleh (Liandy Lumban Tobing, 2021) dalam judul jurnal Pengaruh Motivasi Pelatihan dan Pengembangan Terhadap Kinerja karyawan pada level operator di PT. Subang Autocomp Indonesia dengan hasil penelitian menunjukkan bahwa variabel Motivasi berpengaruh paling dominan terhadap kinerja karyawan sebesar 46,2\% dibandingkan dengan variabel pelatihan dan pengembangan sebesar 31,7\%.Dalam jurnal yang ditulis oleh (Ekhsan, 2019) menyimpulkan bahwa motivasi merupakan salah satu factor dalam meningkatkan kinerja karyawan yaitu dengan adanya perhatian yang diberikan pemimpin untuk kesempatan kepada karyawannya berprestasi dan mengembangkan potensi potensi yang ada pada diri karyawan untuk lebih mengeksplorasi kreatifitas yang dimiliki, dengan demikian perusahaan akan menghasilkan kinerja karyawan yang baik dan berkualitas.

3) Nilai koefisien regresi variabel Kepemimpinan $\left(\mathrm{X}_{2}\right)$ terhadap variabel Kinerja ( $\mathrm{Y}$ ) adalah sebesar 82,8\%. Ini memberikan pengertian jika variabel Kepemimpinan $\left(\mathrm{X}_{2}\right)$ naik sebesar 1 persen, maka hal tersebut akan meningkatkan variabel Kinerja (Y) sebesar 82,8\% dengan asumsi bahwa variabel Motivasi $\left(\mathrm{X}_{1}\right)$ dianggap konstan atau tidak berubah. Hal ini mengartikan semakin meningkatnya kepemimpinan maka akan semakin meningkat pula kinerja karyawan. Berdasarkan hasil jawaban dari 48 responden yang diperoleh dari kuisioner menunjukkan bahwa kepemimpinan berada pada skala baik. sejalan dengan penelitian yang dilakukan oleh (Parashakti \& Setiawan, 2019) dalam judul jurnal Gaya Kepemimpinan dan Motivasi terhadap Kinerja Karyawan pada Bank BJB Cabang Tangerang dengan hasil penelitian menunjukkan bahwa gaya kepemimpinan paling dominan berpengaruh terhadap kinerja sebesar 2,9\% dibandingkan variabel motivasi sebesar 33,2\%. Ini berarti kepemimpinan dapat membentuk kinerja karaywan yang baik. Begitupun dengan penelitian (Inaray, 2016) dalam judul jurnal Pengaruh Kepemimpinan dan Motivasi kerja terhadap kinerja karyawan pada PT. Amanah Finance di Manado dengan hasil penelitian bahwa kepemimpinan berpengaruh terhadap kinerja karyawan sebesar 39,06\% ini menjelaskan bahwa fungsi kepemimpinan merupakan salah satu cara diantara peran administrator dalam rangka mempengaruhi orang lain atau para bawahannya agar mau 
dengan senang hati untuk mencapai tujuan organisasi yang telah ditetapkan.

\section{Kesimpulan}

Berdasarkan hasil penelitian, maka dapat ditarik kesimpulan bahwa adanya pengaruh secara signifikan antara variabel Motivasi secara parsial terhadap kinerja karyawan di Bank Rakyat Indonesia cabang Karawang. Artinya semakin tinggi tingkat motivasi seorang karyawan maka akan semakin tinggi pula tingkat kinerja karyawan tersebut. Hal ini akan berdampak baik pada perusahaan.

Begitu pula dengan variabel Kepemimpinan secara parsial berpengaruh secara signifikan terhadap kinerja karyawan di Bank Rakyat Indonesia cabang Karawang Semakin baik kepemimpinan yang diberikan kepada karyawan maka akan semakin tinggi pula tingkat kinerja karyawan tersebut. Hal tersebut tentu akan berpengaruh positif bagi perusahaan.

Motivasi dan Kepemimpinan secara simultan atau bersama sama berpengaruh positif dan signifikan terhadap Kinerja Karyawan. Berdasarkan hasil dari perhitungan regresi linier berganda menunjukkan bahwa Kepemimpinan lebih dominan pengaruhnya terhadap kinerja karyawan. Sehingga sikap pemimpin di BRI cabang Karawang haruslah diperhatikan dan ditingkatkan dengan bersikap terbuka, peduli, tegas tidak memihak sehingga memotivasi karyawan dalam mencapai tujuan BRI Cabang Karawang

Hasil penelitian dapat digunakan untuk pengembangan ilmu pengetahuan Manajemen Sumber Daya Manusia dibidang Perbankan dengan variabel khususnya Motivasi, Kepemimpinan dan Kinerja Karyawan Bagi peneliti selanjutnya penulis menyarankan untuk memperluas faktor lainnya yang juga berpengaruh terhadap kinerja karyawan. 


\section{BIBLIOGRAFI}

Azuar Juliandi. (2008). Uji Reliabilitas Instrumen Penelitian Dengan Cronbach Alpha: Manual. Medan: Fakultas Ekonomi Universitas Muhammadiyah Sumatera Utara.

Diapari Sosagaon Putra Pane. (2019). Pengaruh Budaya Organisasi, Kepemimpinan, Lingkungan kerja dan Motivasi sebagai variabel intervening Terhadap Kinerja Dosen Politeknik di Kota Bekasi. Syntax Literate: Jurnal Ilmiah Indonesia, 4(9).

Ekhsan, Muhamad. (2019). Pengaruh Motivasi dan Disiplin Kerja terhadap Kinerja Karyawan. Optimal: Jurnal Ekonomi dan Kewirausahaan, 13(1), 1-13.

Fadude, Fikri Djafar, Tawas, Hendra N., \& Poluan, Jane G. (2019). Pengaruh Kepemimpinan, Budaya Organisasi, Dan Kompetensi Terhadap Kinerja Karyawan Pt. Bank Syariah Mandiri Cabang Bitung. Jurnal EMBA: Jurnal Riset Ekonomi, Manajemen, Bisnis Dan Akuntansi, 7(1).

Flippo, edwin B. (1997). Manajemen Personalia. Jakarta: Erlangga.

Hartanto, Selamet B. (2016). Kepemimpinan Dalam Manajemen Pendidikan. Intelegensia: Jurnal Pendidikan Islam, 4(2), 68-77.

Hasibuan. (2015). Manajemen Sumber Daya Manusia. Bandung: Bumi Aksara.

Hidayatulah, Taufiq. (2018). Pengaruh Motivasi Dan Kepuasan Kerja Terhadap Kinerja Karyawan Manufaktur Di Karawang (Studi Kasus Di PT YPMI). Jurnal Manajemen \& Bisnis Kreatif, 3(2).

Inaray, Jelita Caroline. (2016). Pengaruh kepemimpinan dan motivasi kerja terhadap kinerja karyawan pada PT. Amanah Finance di Manado. Jurnal Berkala Ilmiah Efisiensi, 16(2).

Jeli Nata Liyas. (2018). Pengaruh gaya kepemimpinan, motivasi, dan kedisiplinan kerja terhadap kinerja karyawan pada PT. BTN Cabang Syariah Pekanbaru. Al-Masraf: Jurnal Lembaga Keuangan dan Perbankan, 3(2).

Liandy Lumban Tobing, Edi suswardji Nugroho \&. Solehudin. (2021). Pengaruh Motivasi, Pelatihan dan Pengembangan Terhadap Kinerja Karyawan pada level operator di PT. Subang Autocomp Indonesia. Syntax Literate: Jurnal Ilmiah Indonesia, 6(1), 160-172.

Mangkunegara, A. A. Anwar Prabu. (2016). Manajemen sumber daya manusia perusahaan. Bandung: PT. Remaja Rosdakarya.

Parashakti, Ryani Dhyan, \& Setiawan, Dede Irfan. (2019). Gaya Kepemimpinan dan Motivasiterhadap Kinerja Karyawan pada Bank BJB Cabang Tangerang. Jurnal Samudra Ekonomi dan Bisnis, 10(1). 
Pengaruh Motivasi dan Kepemimpinan terhadap Kinerja Karyawan PT. Bank Rakyat Indonesia Cabang Karawang

Prof. Dr. Sugiyono. (2013). Metode Penelitian Manajemen. Bandung:Alfabeta.

Sarinah Sihombing S.Sos.MM, R. Simon Gultom.MM, Sonya Sidjabat, SE.MM. (2015). Manajemen Sumber Daya Manusia. Jakarta: STMT TRISAKTI

Sugiyono. (2017). Metode Penelitian Kuantitatif, Kualitatif, dan R\&D. Bandung: Alfaberta.

Sugiyono, M. (2012). Metode Penelitian Kuantitatif R\&D. Bandung: Alfabeta.

Wibowo. (2016). Manajemen Kinerja (Cetakan Ke). Jakarta: PT Raja Grafindo Persada. 